\title{
Theoretical and Experimental Analysis of Drying Various Geometrical Forms of Red Pepper
}

\author{
A. ONAT ${ }^{a, *}$, A. K. BINARK ${ }^{b}$ \\ ${ }^{a}$ Marmara University, Technical Education Faculty, Energy Department, Istanbul, Turkey \\ ${ }^{b}$ Marmara University, Technology Faculty, Department of Mechanical Engineering, Istanbul, Turkey
}

\begin{abstract}
In this study, a counter flow convection-type dryer was designed and manufactured. During experiments, four different geometrical forms of pepper specimens were dried in a complete (unsliced), perforated, crosscut, and longitudinally sliced forms. For each type of red pepper specimens, the experiments have been conducted at air velocity level of $0.5 \mathrm{~m} / \mathrm{s}$, relative humidity of $10-15 \%$, and temperature of $55-60{ }^{\circ} \mathrm{C}$. The theoretical mathematical model of drying process was developed, considering the pepper's bottom surface to be isolated. The drying curves of experimental results are compared to ones obtained from the theoretical analyses. The comparison showed that experimental results are consistent with the theoretical model. The best results, considering the drying duration, are collected from the specimens sliced longitudinally, which were followed by the crosscut specimens, perforated and unsliced-complete specimens, respectively. $82 \%$ water (humidity) content in $500 \mathrm{~g}$ sample was reduced to $4 \%$ in longitudinally cut samples, $6 \%$ in crosscut samples, $7.5 \%$ in perforated samples and $8 \%$ in unsliced-complete samples, after 14 hours of drying. It is suggested that regarding to easiness of processing, the crosscut red peppers are more suitable, compared to the other geometrical forms.
\end{abstract}

DOI: $10.12693 /$ APhysPolA.127.1388

PACS: 47.54.Bd, 47.54.De, 44.27.+g, 44.30.+v

\section{Introduction}

Being an industrial process, drying is commonly used for drying of products in chemistry, textile, ceramic, construction, timber, pepper and food sectors. The energy used in these sectors for drying has a significant share in total energy consumption. This rate reaches $6 \%$ in chemistry, $5 \%$ in textile, $11 \%$ in ceramic and construction, $11 \%$ in timber, $12 \%$ in food and $33 \%$ in paper sector [1]. Drying is one of the most significant methods used in preserving food products. Dried products can be sent to be further processed or they can be put on market. To preserve food products for a long time without decomposition, dried products can be sterilized. Drying can be used to obtain some products out of solutions and to reduce the mass of carried materials [2]. Turhan and others, in their study, performed drying in regular and irregular pepper stacks at constant temperatures of $50,60,70$ and $80{ }^{\circ} \mathrm{C}$, in a tunnel-type dryer with air speed of $2 \mathrm{~m} / \mathrm{s}$ [3]. Queriox and Nebra dealt in their study with drying kinetics of banana theoretically and experimentally in different drying air conditions. According to constant diffusion coefficient assumption, they determined the humidity content experimentally, during the dying process of banana. The results obtained by taking into consideration the mass flow occurring during banana's shrinkage and transportation on its surface, showed features highly similar with other models. Diffusion and transportation coefficients were obtained by implementing experimental data. Numerical results and experimental results were compared and the most ap-

*corresponding author; e-mail: ayhanonat@marmara.edu.tr propriate transportation limit conditions were obtained using a constant diffusion coefficient [4]. Dinçer and Dost researched humidity and heat conduction performances and humidity transfer parameters of properly cut timber, which is put to drying, Biot coefficient in the ranges of $0<B i<100$ and $B i>100[5]$ were obtained. In their research, Ertekin and Sultanoğlu determined humidity sorption isotherms of green and red pepper at temperatures of 30,45 and $60{ }^{\circ} \mathrm{C}$ and relative humidity values in the range of $10 \%$ to $90 \%$. With nonlinear regression analysis, the acquired experiment results were compared with other solution models [6]. Dinçer theoretically calculated humidity diffusion and humidity conduction coefficients for plane and cylindrical structures for reference range $0<B i<100$ of Biot coefficient, which is the one that is used most in the practice, in his study entitled "modeling of humidity conduction in drying of solid materials". By comparing this theoretical study with experimental studies made by Akiyama for cylindrical structures and by Lewicki for plane structures (flat cut onion wedges), he found the correlation number $\left(r^{2}>0.99\right)$ between drying time and non-dimensional humidity content. Besides, he found Biot number 3.73 for flat cut onion and 0.035 for cylindrical structured starch powder. He calculated diffusion coefficients $5.45 \times 10^{-10} \mathrm{~m}^{2} / \mathrm{s}$ and $3.04 \times 10^{-7} \mathrm{~m}^{2} / \mathrm{s}$ respectively [7]. Simal et al. developed mathematical model for heat distribution during drying in cylindrical structures. Broccoli was cut cylindrically at $0.0070 \pm 0.0014 \mathrm{~m}$ calibre and $0.020 \mathrm{~m}$ long. Then samples were kept in $\mathrm{NaOH}$ solution for 15 seconds at temperature of $100{ }^{\circ} \mathrm{C}$. They performed drying process in a hot air dryer, with a drying temperature between 50 and $90{ }^{\circ} \mathrm{C}$, and with $3 \mathrm{~kg} / \mathrm{m}^{2}$ s air mass flow rate. Drying temperature was attempted to stabilize with an automatic thermostat. Experiments were conducted at air 
velocity of as $2.7 \mathrm{~m} / \mathrm{s}$ and drying temperature of 50,60 , 70,80 and $90^{\circ} \mathrm{C}$. By taking shrinkage into consideration during drying, mathematical model was developed according to Fick's $2^{\text {nd }}$ law. Runge-Kutta-Merson method was used for solution of the problem. Effective diffusion coefficient was determined as a function of humidity and temperature [8]. Pangavhane et al. conducted experiments with Thompson seedless raisin in a fixed-type commercial dryer with air velocity of $0.25,0.50,0.75$ and $1.0 \mathrm{~m} / \mathrm{s}$, temperature of $50,60,70$ and $80{ }^{\circ} \mathrm{C}$, and relative humidity of $13 \%, 18 \%$ and $23 \%$. They performed weighting measurement at every half an hour until the humidity content in raisin was $17 \%$. As a result of experimental and theoretical studies, drying kinetics of thin shelled seedless Thompson raisin was solved with Page equality. Experimental and theoretical results showed similar values. It was observed that abrupt changes occur in the structure of raisin above drying temperature of $70{ }^{\circ} \mathrm{C}$ and its shell has shriveled and cracked. They stated that the most appropriate drying temperature is between $50-70{ }^{\circ} \mathrm{C}[9]$. Doymaz and Pala conducted a theoretical and experimental study of the drying kinetics of red peppers under different pretreatment and air drying conditions [10]. Scala and Crapiste simulated the process of drying of individual pieces of red pepper under constant external conditions and, to predict changes in some nutritional and organoleptic attributes of the product. Water sorption isotherms of red pepper were determined in the range $20-50{ }^{\circ} \mathrm{C}$ and represented by two different sorption equations. Drying kinetics was described by a diffusive model, the effective moisture diffusivity ranging from 5.01 to $8.32 \times 10^{-10} \mathrm{~m}^{2} / \mathrm{s}$ with an activation energy of $23.35 \mathrm{~kJ} / \mathrm{mol}$ were obtained. Degradation kinetics for ascorbic acid and total carotenoids were measured in the range $50-70{ }^{\circ} \mathrm{C}$ and modeled as the first-order reactions [11]. Faustino at al. studied the drying of green peppers, in terms of drying kinetics evaluated at $30{ }^{\circ} \mathrm{C}$, $40{ }^{\circ} \mathrm{C}, 50{ }^{\circ} \mathrm{C}, 60{ }^{\circ} \mathrm{C}$ and $70{ }^{\circ} \mathrm{C}$, and fitted experimental data to different empirical kinetic models from literature. This kinetic study was then complemented with the modeling in terms of Fick's diffusion equation [12]. Vega et al. studied and modeled the drying kinetics of the red bell pepper at different temperatures $(50,60,70$ and $80{ }^{\circ} \mathrm{C}$ ), using air velocity of $2.5 \mathrm{~m} / \mathrm{s}$. They observed only the falling rate period during the experiment. Effective moisture diffusivity was estimated to be between $3.2 \times 10^{-9}$ and $11.2 \times 10^{-9} \mathrm{~m}^{2} \mathrm{~s}^{-1}$ within the studied temperature range [13].

\section{Materials and methods}

\subsection{Solar supported counter-flow convection dryer}

Thermal input, required for the drying, was provided from two heat sources, a reflective sun-light collector and an additional sensitive resistance heater. When the external air is brought into the system via a duct, its temperature is being increased by the resistive heater. Hot air is directed onto the conveyor belt by a blowing fan. After passing over the drying peppers, having opposite flow direction, drying air is discharged at heat transformer, in which heat storage is performed in a PCM (Phase Change Material) with the help of air suction fan. In this way, heat recovery is achieved by discharging the the used hot air over PCM and over the intake air. Device's band speed can be changed between 0 and $0.05 \mathrm{~m} / \mathrm{s}$ with the inverter (speed control device), connected to motor-reductor group which is connected with band using a belt-pulley mechanism. Thus, the time between the entry and the exit of a spot on the band can be reduced down to 1.27 minutes. In this way, product drying time can be changed with the change of speeds at a stable tunnel length, thus the opportunity to dry different products is created. Supply and exhaust fans were employed in the experimental setup. Supply fan is of a radial type. Since it has a rotational speed control facility it is possible to send the air into the collector with varying speeds. Temperature control in the collector was performed by a PC connected PLC.

Drying different products with the aid of computer program is achieved with additional heater, at different temperatures, according to entered drying values. The designed and manufactured solar supported counter flowconvection type dryer is presented in Fig. 1. Front view of counter flow-convection type dryer is shown in Fig 1a. Side view of counter flow-convection type dryer is shown in Fig 1b. Product and air flow diagram of counter flowconvection type dryer is shown in Fig. 1c. (a)

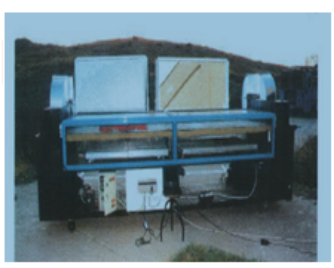

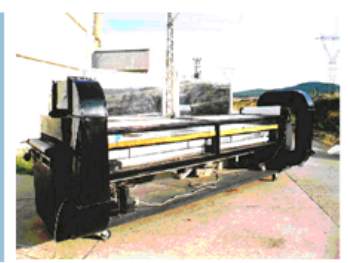

(b)

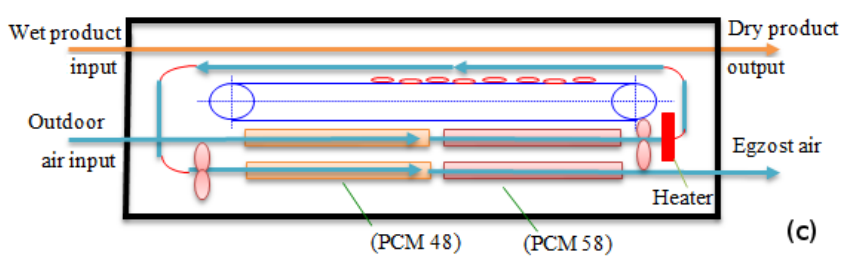

Fig. 1. Designed and manufactured solar-supported counter flow-convection type dryer, (a) front view, (b) side view, (c) product and air flow diagram.

\subsection{Determination of the amount of dry and wet material in peppers}

Drying oven method is used in this study to determine the amount of moisture in peppers. In order to determine the amount of dry material and of moisture, samples were weighted every two hours during processing at $110{ }^{\circ} \mathrm{C}$ in the drying oven. Measurements continued until the change between two measurements was less then $0.04 \%$. This period lasted approximately 70 hours. Pepper with 
total mass of $100 \mathrm{~g}$ was cut and turned into samples with a mass of roughly $3 \mathrm{~g}$. They were weighted on scales with 250 g capacity and $1 / 1000$ sensitivity. Differences of the change rate of amount of dry material and moisture appeared, depending on the type of pepper, different ways of growing, measurement errors, and seed loss in pepper, which was cut in different shapes and depending on the air speed during the measurement. The amount of dry material was found to be $18 \%$, and that of moisture was $82 \%$. In order to determine the humidity of the air, temperatures of a wet and a dry thermometer were measured. Samples of different geometrical shapes prepared for drying are presented in Fig. 2. Unsliced-complete red pepper is shown in Fig. 2a. Perforated red pepper is shown in Fig. 2b. Crosscut red pepper is shown in Fig. 2c. Longitudinally red pepper sliced lengthwise is shown in Fig. 2d.

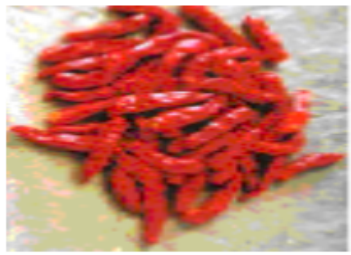

(a)

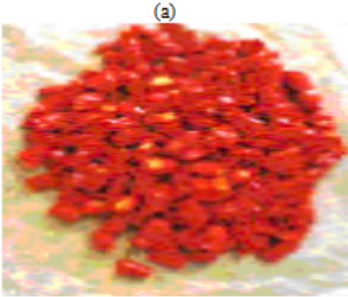

(c)

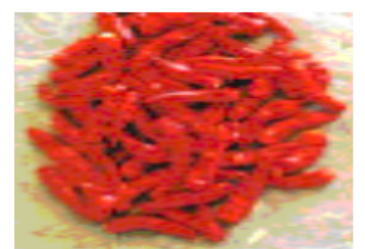

(b)

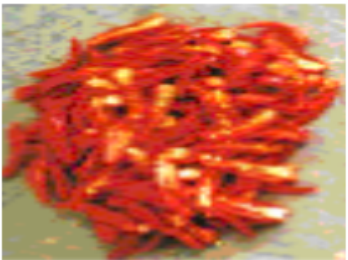

(d)
Fig. 2. Red pepper of different geometrical forms prepared for drying, (a) unsliced-complete red pepper, (b) perforated red pepper, (c) crosscut red pepper (d) longitudinally sliced red pepper.

\subsection{Mathematical model}

According to Fick's $2^{\text {nd }}$ Law, for single dimension of Cartesian coordinate system, humidity loss that occurs in pepper stacks of thickness along $z$-axis can be written as follows.

$$
\frac{\partial X_{f}}{\partial t}=D \frac{\partial^{2} X_{f}}{\partial z^{2}}
$$

where $D\left(\mathrm{~m} / \mathrm{s}^{2}\right)$ is the diffusion coefficient, $t(\mathrm{~s})$ is time and $z(\mathrm{~m})$ is the change of pepper stack height. For boundary conditions it is assumed that the infinite plate of thickness $2 L$, and initial temperature $T_{0}$ is suddenly brought into contact with a fluid with temperature $T_{\infty}$. With such boundary conditions, this equation can be solved by thinking of it as a mass transfer equivalent of heat transmission's process in a transient state [14]. If $X_{\infty}$ is defined and written as $\bar{X}=X_{f}-X_{\infty}$, based on the humidity of the air, we obtain

$$
\frac{\partial \bar{X}}{\partial t}=D \frac{\partial^{2} \bar{X}}{\partial z^{2}}
$$

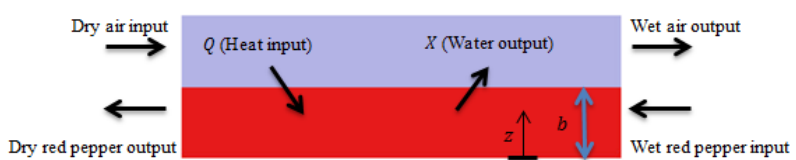

Fig. 3. Diagrammatic presentation of drying process.

According to drying system presented in Fig. 3, the initial and the boundary conditions for system are:

$$
\begin{aligned}
& t=0,0 \leq z \leq b, \bar{X}=\bar{X}_{b}=X_{b}-X_{\infty} \\
& t>0, z=b-\left.D \frac{\partial \bar{X}}{\partial z}\right|_{z=b}=\left.h^{\prime} \bar{X}\right|_{z=b} \\
& t>0, z=\left.0 \frac{\partial \bar{X}}{\partial z}\right|_{z=0}=0,
\end{aligned}
$$

where $b(\mathrm{~m})$ is thickness of pepper meat and $h^{\prime}(\mathrm{m} / \mathrm{s})$ is mass transfer coefficient. Solution of (2) is considered as a product of two functions, one of which depends on coordinate $z$ and the other depends on time $t$ time.

Using definition of Fourier number $F o_{m}=\frac{D t}{b^{2}}$, the time-dependent solution is obtained as

$$
\begin{aligned}
& \frac{\bar{X}}{\bar{X}_{b}}=2 \sum_{n=0}^{\infty} \frac{\sin \left(\lambda_{n} b\right)}{\lambda_{n} b+\sin \left(\lambda_{n} b\right) \cos \left(\lambda_{n} b\right)} \\
& \quad \times \cos \left(\lambda_{n} z\right) e^{-\left(\lambda_{n} b\right)^{2} F o_{m}} .
\end{aligned}
$$

As a result of the numerical calculations, Biot number $\left(B i=\frac{h^{\prime} b}{D}\right)$ is found to be 112309 for all uncut peppers. For other shapes of red pepper samples, since these values are practically $B i_{m}>100$, it can be taken as $B_{i_{m}} \rightarrow \infty$ [15]. By using relative equations with Biot number, coefficients of Eq. 3 are found. By inserting these coefficients into general solution, if $\bar{X}=X_{f}-X_{\infty}$ and $F o_{m}$ transformations are written in their place in equation, if a solution is conducted for $1^{\text {st }}$ term along $(z)$ axis in pepper stacks of $(b)$ thickness, equation (4) that shows the humidity loss $\left(X_{f}\right)$, occurred in red pepper stacks is acquired.

$$
\frac{\bar{X}_{f}-\bar{X}_{\infty}}{\bar{X}_{b}-\bar{X}_{\infty}}=\left[\cos \left[\frac{\pi}{2 b} z\right] \exp \left[-\frac{\pi^{2}}{4} \frac{D t}{b^{2}}\right]\right] \text {. }
$$

\section{Results and discussion}

The weight loss in pepper samples of different geometrical forms is calculated with measurements performed every 2 hours at a scales with $1 / 1000$ sensitivity. Results of experimental studies: air speed $0.5 \mathrm{~m} / \mathrm{s}$, relevant humidity rate $10-15 \%$ and drying temperature are calculated as $55-60{ }^{\circ} \mathrm{C}$. Weight loss of red peppers in different geometrical shapes, obtained as a result of experiment is presented in Table I and the humidity loss (\%) is presented in Table II and Fig. $4.82 \%$ of water (humidity) in $500 \mathrm{~g}$ sample were reduced to $4 \%$ in longitudinally sliced samples, to $6 \%$ in crosscut samples, to $7.5 \%$ in perforated samples and to $8 \%$ in unsliced-complete samples after 14 hours of drying. 
Measurement of mass (g) of red peppers with

TABLE I different geometry, as function of time.

\begin{tabular}{c|c|c|c|c|c|c|c|c|c}
\hline \hline Drying time, $[\mathrm{h}]$ & 0 & 2 & 4 & 6 & 8 & 10 & 12 & 14 & $\mathrm{KMM}$ \\
\hline Unsliced & 500 & 375 & 264.7 & 152.5 & 118.4 & 109.5 & 101.1 & 97.8 & 90 \\
Perforated & 500 & 360 & 225 & 142.9 & 118.4 & 107 & 98.9 & 97.2 & 90 \\
Crosscut & 500 & 300 & 176.5 & 121.6 & 111.1 & 104.5 & 97.8 & 95.7 & 90 \\
Longit. sliced & 500 & 272.7 & 157.9 & 115.4 & 107.1 & 102.2 & 95.7 & 93.7 & 90
\end{tabular}

Humidity (\%) of red peppers of different ge- TABLE II ometry as a function of time.

\begin{tabular}{c|c|c|c|c|c|c|c|c}
\hline \hline Drying time, [h] & 0 & 2 & 4 & 6 & 8 & 10 & 12 & 14 \\
\hline Unsliced-compl. & 0.82 & 0.76 & 0.66 & 0.41 & 0.24 & 0.16 & 0.11 & 0.08 \\
Perforated & 0.82 & 0.75 & 0.60 & 0.37 & 0.24 & 0.14 & 0.09 & 0.075 \\
Crosscut & 0.82 & 0.70 & 0.49 & 0.26 & 0.19 & 0.12 & 0.08 & 0.06 \\
Longitud. sliced & 0.82 & 0.67 & 0.43 & 0.22 & 0.16 & 0.10 & 0.06 & 0.04
\end{tabular}

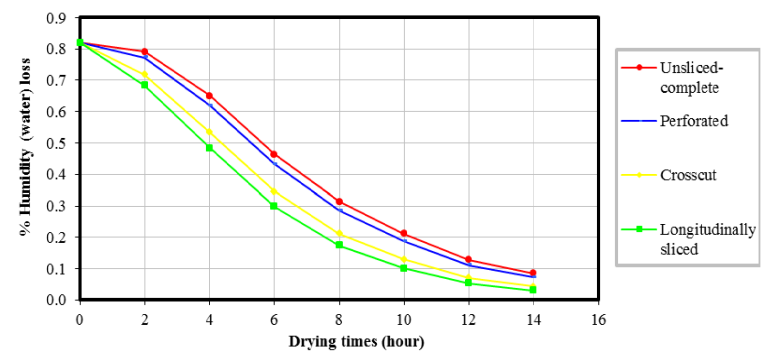

Fig. 4. Humidity (water) loss of red peppers in different geometrical shapes.

By using equation (4), obtained as a result of theoretical analysis, humidity losses $\left(X_{f}\right)$ occurred along $z$ axis, as functions of time, in pepper stacks of width $b$ were calculated. Experimental results obtained by measurements performed in opposite flow transport type dryer and theoretical results are compared in the same graphic for peppers with different geometrical shapes. Figure 5a shows comparison of drying curves for unsliced-complete, Fig. 5b for perforated, Fig. 5c for crosscut, and Fig. 5d for longitudinally sliced red peppers. During the first two hours, the humidity loss in unsliced-complete and perforated red peppers was too small to be noticeable and supplied energy helped the product to heat and to propagate heat from the surface to inner layers. The membrane shell between red peppers delayed the transmission of heat to products inside.

Ash content (weight percentage).

TABLE III

\begin{tabular}{c|c|c|c}
\hline \hline \multirow{2}{*}{ Samples } & Amount & \multicolumn{2}{|c}{ Most wanted in TS 2419 } \\
\cline { 3 - 4 } & {$[\%]$} & I. Class & II. Class \\
\hline Unsliced-complete & 9.3 & 8.5 & 10.0 \\
Perforated & 7.9 & 8.5 & 10.0 \\
Crosscut & 7.7 & 8.5 & 10.0 \\
Longitudinally sliced & 7.7 & 8.5 & 10.0
\end{tabular}

However, since the membrane shell was torned in the crosscut and longitudinally sliced red peppers, heating occurred in a shorter period of time and humidity loss started immediately. Thus the humidity loss in samples
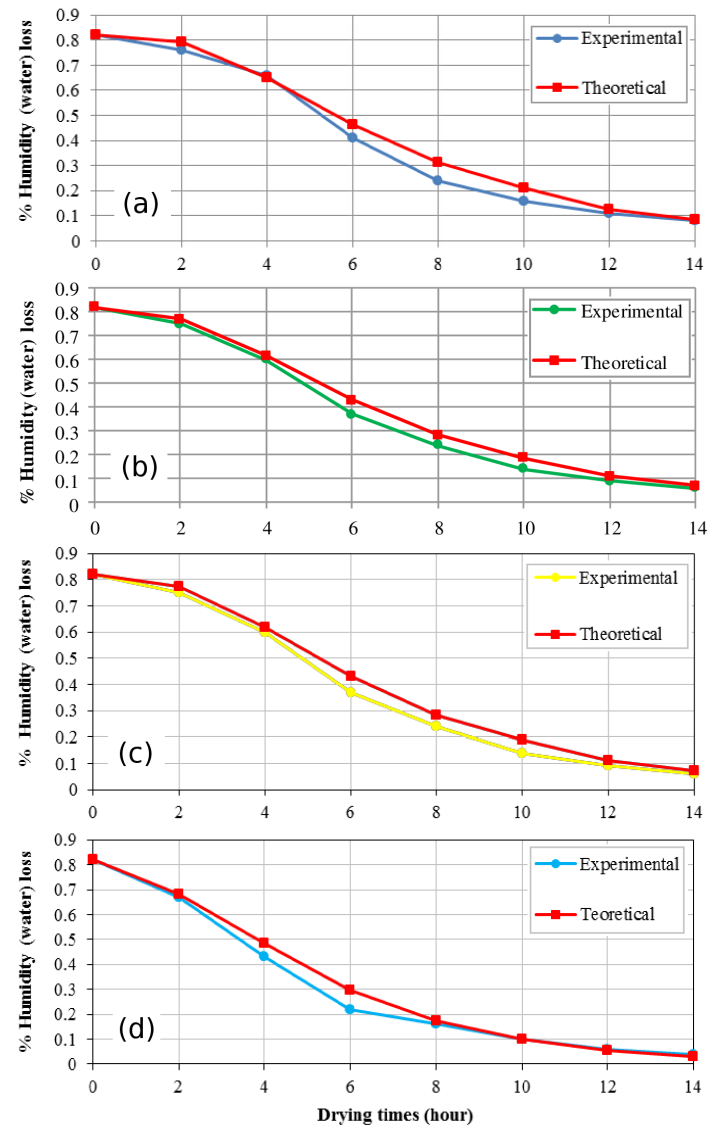

Fig. 5. Comparison of experimental and theoretical time-depended humidity (water) loss (\%) of unslicedcomplete red peppers (a), of perforated red peppers (b), of crosscut red peppers (c) and of longitudinally sliced red peppers $(\mathrm{d})$.

Colour determination.

TABLE IV

\begin{tabular}{c|c|c}
\hline \hline Samples & Colour value & ASTA colour value \\
\hline Unsliced-complete & 91.3 & $70-150$ ASTA \\
\hline Perforated & 94.1 & $70-150$ ASTA \\
\hline Crosscut & 116.3 & $70-150$ ASTA \\
\hline Longitudinally sliced & 119.1 & $70-150 \mathrm{TA}$
\end{tabular}

is decreasing in following order: in longitudinally sliced, crosscut, perforated and unsliced-complete samples. The ash contents and colours of samples obtained after drying are presented in Table III and Table IV respectively.

\section{Conclusions}

In the opposite flow type dryer device which was designed and produced, by taking advantage of Fick's $2^{\text {nd }}$ law, mathematical model of time-depended humidity loss, which occures along $z$ axis in a red pepper stack of width $b$ is prepared. A comparison of the results, obtained in experiments performed by a weight loss method, and the theoretical results obtained as a result of mathematical modeling was carried out. It is determined that with the exception of the uncut red peppers, the theoretical and experimental results are highly similar and that 
are in accordance with each other. It is found that the change difference between theoretical drying curve and experimental drying curve in all uncut red peppers is a little higher than in other samples, and that this is the result of the air gaps between the uncut pepper stacks.

Comparison of the drying periods of red pepper samples, which are dried in different geometrical shapes, shows that the shortest drying time was obtained in longitudinally cut samples, followed by the cross cut, perforated and whole red pepper samples. $82 \%$ water (humidity) ratio in $500 \mathrm{~g}$ sample was reduced to $4 \%$ in longitudinally cut samples, $6 \%$ in crosscut samples, $7.5 \%$ in perforated samples and $8 \%$ in uncut whole samples after 14 hours of drying. However, if the processing facilitation is considered, based on automation possibilities, it is suggested to crosscut red peppers in pepper drying processes.

\section{References}

[1] A.S. Mujumdar, Handbook of Industrial Drying, 28, New York, 1987.

[2] N. Özbalta, A. Güngör, Kurutma Sistemlerinde I Pompar Kullaim Potansiyeli, Ege University, Solar Energy Institute, 5, İzmir, 1998.

[3] M. Turhan, K.N. Turhan, F. Sahbaz, Journal of Food Processing and Preservation 21, 223 (1997).
[4] M.R. Querioz, S.A. Nebra, Journal of Food Engineering 47, 127 (2001).

[5] I. Dinçer, S. Dost, Wood Science and Technology 30, 245 (1996).

[6] F.G. Ertekin, M. Sultanoğlu, Journal of Food Engineering 47, 225 (2001).

[7] I. Dinçer, Moisture Transfer Models for Solid Drying, $12^{\text {th }}$ International Drying Symposium (2002).

[8] S. Simal, C. Rossello, A. Berna, A. Mulet, Journal of Food Engineering 37, 423 (1998).

[9] D.R. Pangavhane, R.L. Sawhney, P.N. Sarsavala, Journal of Food Processing and Preservation 24, 335 (2000).

[10] I. Doymaz, M. Pala, Journal of Food Engineering 55, 331 (2002)

[11] K.D. Scala, G. Crapiste, Food Science and Technology 41, 789 (2008).

[12] J.M.F. Faustino, M.J. Barroca, R.P.F. Guine, Food and Bioproducts Processing 85, 163 (2007).

[13] A. Vega, P. Fito, A. Andres, R. Lemus, Journal of Food Engineering 79, 1460 (2007).

[14] O.F. Genceli, Çözümlü Isı Illetim Problemleri, Birsen Pub., Istanbul, p.320-323, 2000.

[15] O.F. Genceli, Momentum-Heat Transfer Lecture Notes, Istanbul Technical University, Istanbu, 2000. 